\title{
Melanotic mucin-producing neuroepithelial neoplasm of mesencephalon with consideration of similar tumours in different locations
}

\author{
SAMRUAY SHUANGSHOTI \\ From the Department of Pathology, Faculty of Medicine, Chulalongkorn University, Bangkok, Thailand
}

SUMMARY A six month old boy had a mesencephalic melanotic neoplasm of the neuroepithelial derivatives which produced mucin. Location in the mesencephalon and production of the mucin have not been described previously for this kind of intracranial tumour. The various cellular elements within the growth are in accord with diverse differentiations of the neuroepithelium of the neural tube, the neuroectodermal part of the neural crest, or both. Derivatives of the neural tube and crest can be melanotic, and some neuroepithelial derivatives (ependyma, oligodendrocyte, and choroidal epithelium) produce mucin. Hence, melanotic neuroepithelial neoplasms with mucinous product can occur. The present tumour is similar to lesions variously designated as melanotic medulloblastoma, retinal anlage tumour, and progonoma. Diverse differentiation of the neuroepithelium of the neural tube, or of the neuroectodermal part of the neural crest, or both would create these variously named tumours. The frequency of melanotic neuroepithelial neoplasms in infancy, and the presence of papillae strongly suggest congental derivation.

We noted a primary malignant melanoma of the leptomeninges in our previous study of 1028 intracranial tumours, but did not see any melanotic neuroepithelial neoplasm. ${ }^{1}$ We also described two unique cases of melanosis of nonneoplastic neuroepithelial derivatives viz the epithelium of the choroid plexuses, ${ }^{2} 3$ ependyma, subependymal neuroglia, and dentate and trigeminal motor nuclei. ${ }^{3}$ In this communication, we record a melanotic tumour of neuroepithelial origin, arising in the mesencephalon and producing mucin.

\section{Case report}

A six month old boy was the product of an uncomplicated pregnancy and term delivery. The postnatal development was unremarkable until two weeks before hospitalisation when he had fever, nasal discharge, cough, and vomiting. The parents also noticed that his head was remarkably large. In hospital, he was found to have a bulging anterior fontanelle and wide separation of the cranial sutures.

Body temperature was $38^{\circ} \mathrm{C}$; pulse rate, $120 / \mathrm{min}$;

Address for reprint requests: Professor S Shuangshoti, Chulalongkorn Hospital, Bangkok 5, Thailand.

Accepted 14 April 1980 respiratory rate, $28 / \mathrm{min}$; and body weight, $5750 \mathrm{~g}$. The respective circumference of the head and chest was 46 and $40 \mathrm{~cm}$. The alert patient did not have localising signs. Examination of other systems of the body revealed normal findings. However, isotope brain scan showed a large area of abnormal uptake of the radioactive substance in the middle part of the midline of the posterior cranial fossa and just above the base; a mass within the midbrain was suspected. A ventriculogram showed symmetrical dilatation of both lateral and third ventricles. A pneumoencaphalogram showed a mesencephalic mass.

A ventriculoperitoneal shunt inserted on the 24th day of hospitalisation was followed by decrease in the size of the head, but the patient was stuporous and febrile. The body weight declined from 5750 to $4700 \mathrm{~g}$. On the 44th day of admission, a suboccipital craniotomy disclosed a mesencephalic tumour lying beneath the tentorium and projecting caudally over the brainstem. It was loosely adherent to the anterior aspect of the cerebellar midline, firm, nodular, and grey. After easy separation of the lesion from the cerebellum, the superficial part was excised. The raw surface and the removed fragments of the growth were focally black. The deep portions of the tumour over the brainstem and in the mesencephalon were left behind. The patient recovered uneventfully from the operation, but still was stuporous and febrile. He died in coma after two months of hospitalisation. 
A necropsy was not permitted.

The combined tissue fragments S-17-6164 measured $3 \mathrm{~cm}$ in diameter and were stained with haematoxylin and eosin ( $\mathrm{H}$ and $\mathrm{E})$. Mallory's phosphotungstic acid haematoxylin (PTAH), Masson's trichrome, Gomori's stain for reticulin fibres, Mayer's mucicarmine, periodic acid-Schiff (PAS) with and without diastase digestion, Gomori's stain for iron, Fontana-Masson's method for melanin and Nissl's stain for tigroid substance were also used. Some sections were bleached with an aqueous solution of potassium permanganate.

Microscopically, the lesion exhibited widely disseminated dark and pale foci containing various types of neoplastic cells (fig 1A). Cells in the dark foci ranged from large to small sizes. They were arrayed in clusters, sheets, strands, papillae with cores of connective tissue and small blood vessels (fig 1B), or were scattered individually. The large and medium tumour cells had epithelial outlines with vesicular nuclei and occasional distinct nucleoli. Frequently, they formed true rosettes, tubules, and clefts (fig 1B and $\mathrm{C})$. The pale acidophilic cytoplasm was often filled by numerous deep brown granules of pigment which were black in Fontana-Masson's stains, decolorised by potassium permanganate solution, and were non-reactive in Gomori's stains for iron. The pigment was therefore considered to be melanin. These melanin granules (fig $1 \mathrm{~B}$ and $\mathrm{C}$ ) were so abundant in several epithelium-like tumour cells that cellular outlines of ten were obscured. Moreover, the mucicarminophilic, PAS-reactive but diastaseresistant material was present in some epithelium-like tumour cells (fig 2A) as well as in the stroma, parti- cularly in those areas where the epithelium-like cells were scattered. The substance was regarded as mucin and mucopolysaccharide. Occasionally, the epithelium-like cells exhibited blue processes in the PTAH preparations; they were interpreted as ependymal. The undifferentiated small cells were rounded (fig 2B). The dark nuclei were rimmed by scanty perikaryon. Nucleoli were rarely seen. The cells also contained cytoplasmic granules of melanin. Mitotic figures were moderate in number in both ependymal cells and undifferentiated small cells.

The pale region of the lesion consisted of loose meshes of tumour cells which of ten had angular outlines and blue processes in the PTAH preparations. In $\mathrm{H}$ and $\mathrm{E}$ stained sections, these exhibited pale eosinophilic and homogenous cytoplasm; the ovoid and vesicular nuclei had indistinct nucleoli. Occasionally, these tumour cells mingled with the ependymal cells and the undifferentiated small cells. They were considered as neoplastic astrocytes (fig 2C); a few of them contained cytoplasmic granules of melanin. Moreover, the pale zone had a few large and rounded cells in clusters, or mingled with the astrocytes. The distinctly clear perikaryon was occasionally interspersed by granules of melanin. The rounded nuclei were dark, but not as dark as those of the undifferentiated small cells. The cells were interpreted as neoplastic oligodendroglia (fig 3A and B). Neurons were not observed.

The stroma of the tumour consisted of many collagen fibres, a few reticulin fibres, and sparse small blood vessels which did not exhibit endothelial hyperplasia. Occasionally, the reticulin fibres (fig 3C) traversed groups of the various tumour cells, but

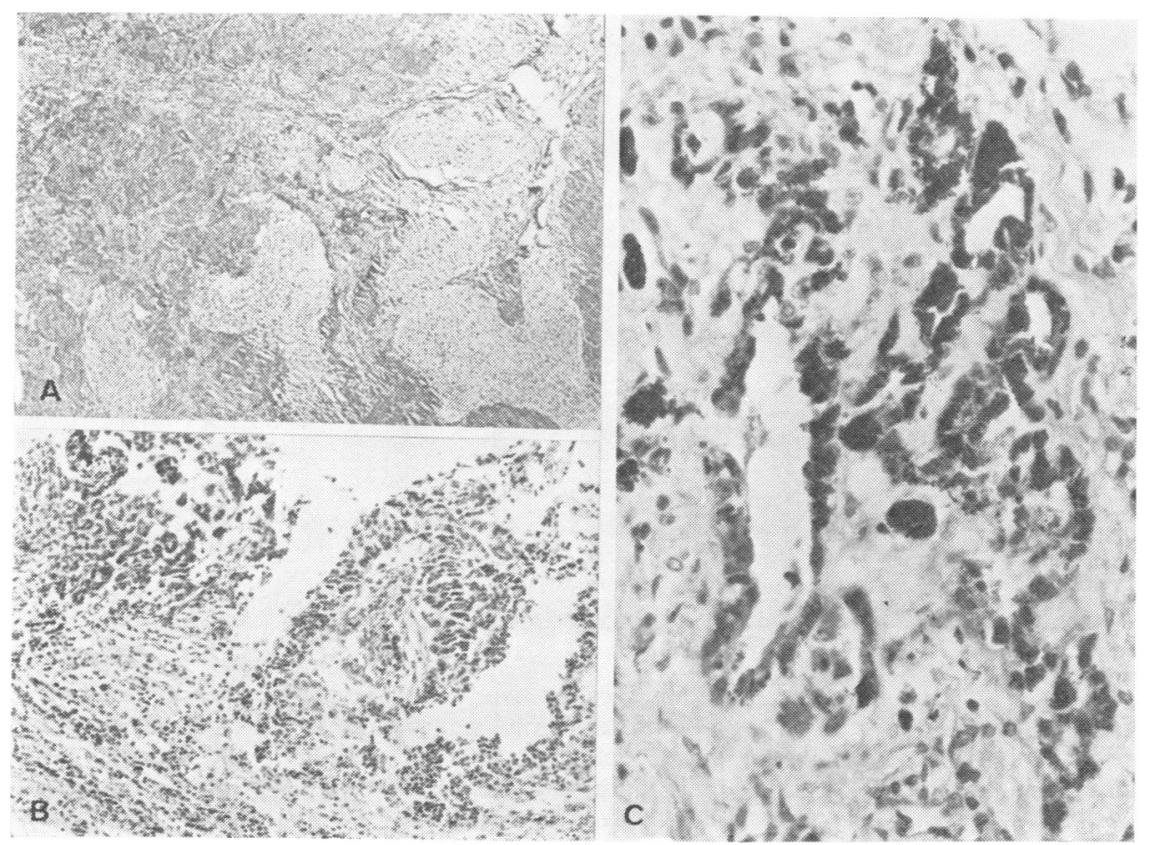

Fig 1 (A) photomicrograph showing dark and pale foci within the tumour $(H$ and $E, \times 30)$; (B) a papilla consisting of vascular connective tissue core covered by stratified tumour cells. Many true rosettes of radically-arranged neo-plastic cells, and scattered tumour cells at random are exhibited. Melanin granules within the tumour cells are not clearly visible at this magnification ( $H$ and $E$, $\times 65)$; $(C)$ tubules of melanin-laden epithelium-like cells, interpreted as ependymal, cluster in the connective tissue stroma (H and E, $\times 260)$. 


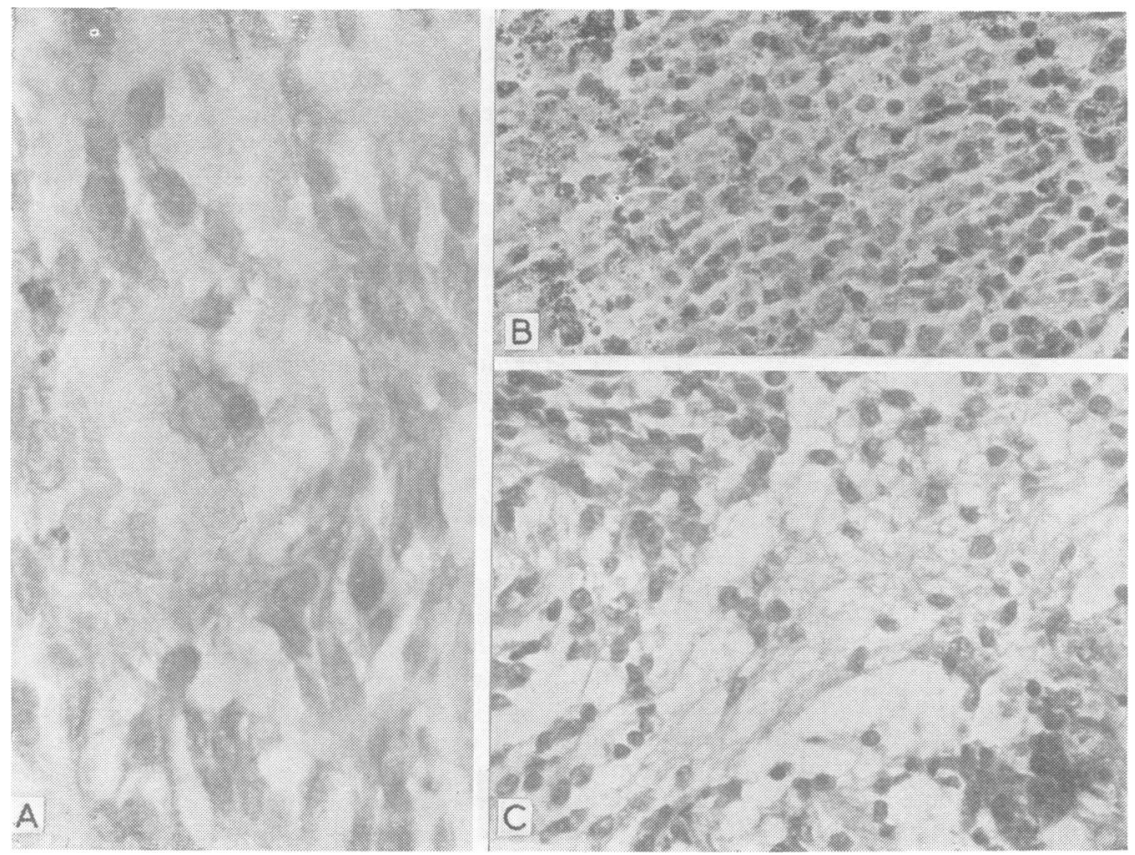

Fig 2 (A) intracellular and extracellular mucin within the tumour is demonstrated. $A$ neo-plastic cell toward the centre of the photo-micrograph contained a distinct cytoplasmic globule of mucin (Mayer's mucicarmine stain, $\times 640) ;(B)$ undifferentiated small and rounded tumour cells containing melanin granules are shown $(H$ and $E, \times 260) ;(C) a$ mesh of neoplastic astroglia with processes is demonstrated ( $\mathrm{H}$ and $E, \times 260)$.

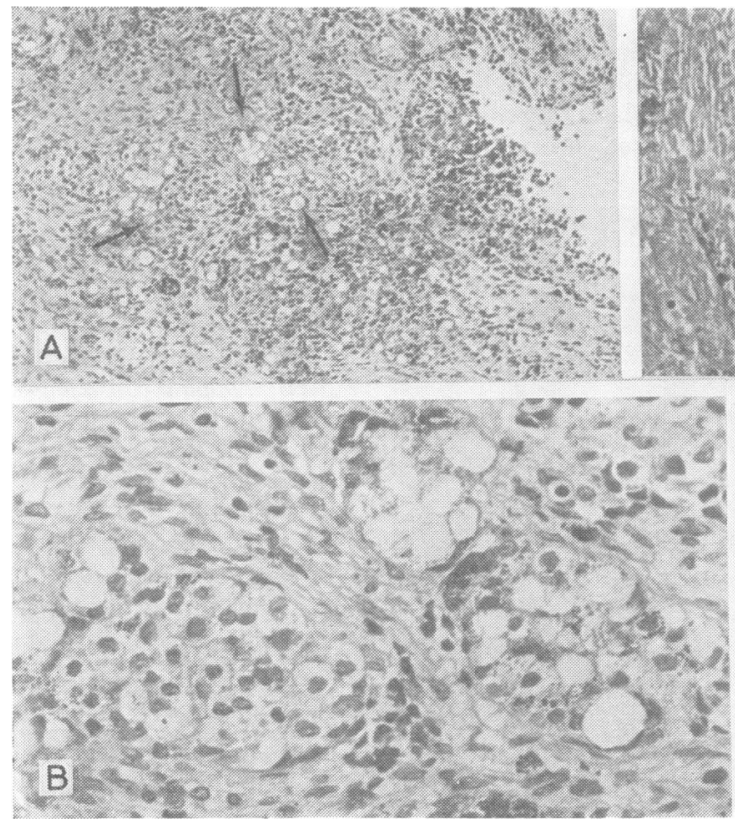

did not wrap around the individual neoplastic cells. They were most likely leptomeningeal in origin because only the superficial part of the growth was excised surgically; the leptomeninges would be included in the specimen.
Fig 3 (A) neoplastic oligodendroglia are clustered as well as disseminated randomly within the stromal connective tissue. Melanin granules are present but not seen distinctly at this magnification. The arrows indicate a few clusters of oligodendroglia which are further exhibited in $B$ ( $H$ and $E$, $\times 26)$; $(B)$ the clear perikaryon of the oligodendrocytes is occasionally interspersêd by melanin granules $(H$ and $E, \times 260) ;(C)$ a few reticulin fibres traverse groups of tumour cells. Note their absence among individual tumour cells (Gomori's reticulin stain, $\times 65)$.

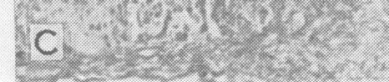

The lesion was considered to be a melanotic mucin-producing neuroepithelial neoplasm of the mesencephalon (mixed ependymoma, astrocytoma, oligodendroglioma, and undifferentiated neuroepithelial derivatives). In view of the easy separation 
from the anterior part of the cerebellar midline during surgical intervention, it was concluded that the tumour did not originate in the cerebellum.

\section{Discussion}

General considerations and differential diagnoses The term "neuroepithelium" as used here is regarded as analogous to the term "neuroectoderm." We consider the present tumour to be of the same type as the 12 intracranial melanotic neoplasms previously reported by such diverse names and locations as the following: malignant melanin-forming tumour "akin to medulloblastoma of the cerebellar vermis and fourth ventricle" (1 case), ${ }^{4}$ pigmented papillary medulloblastoma of the cerebellar vermis and fourth ventricle ( 2 cases), ${ }^{56}$ melanotic progonoma of the third ventricle ( 1 case) ${ }^{7}$ and of the fourth ventricle (4 cases), ${ }^{8}$ medulloblastoma-like tumour with melanin formation of the probable pineal region ( 1 case), ${ }^{9}$ melanotic medulloblastoma of the cerebellar vermis and fourth ventricle (1 case), ${ }^{10}$ melanotic neuroectodermal tumour of the cerebellar vermis and fourth ventricle ( 1 case) ${ }^{11}$ and melanotic ependymoma of the left temporal lobe (1 case). ${ }^{12}$ Our example brings the total cases to 13. Thus, cerebellar vermis and fourth ventricle are the most common sites of occurrence of these melanotic tumours (9 cases). ${ }^{4-8} 1011$ Only in two examples were the growths in adults (aged 21 and 30 years, respectively). ${ }^{11} 12$ The others were children ranging in age from 3.5 months to 8 years. The sex was not stated in five cases. ${ }^{6} 8$ Of the remaining eight patients, seven were male, and one was female.

Stowens and $\operatorname{Lin}^{7}$ and Hahn et $a^{11}$ regarded their cases to be similar to 76 extracranial melanotic tumours reported by such names as congenital melanocarcinoma, melanotic epithelial odontoma, atypical melanoblastoma, melanotic adamantinoma or ameloblastoma, melanoameloblastoma, melanotic congenital tumour, pigmented retinoblastoma, pigmented epulis, odontogenic hamartoma, retinal anlage tumour, retinal or retinoblastic teratoma, retinal choristoma, oral glioma, melanotic progonoma, melanotic anlage tumour, and melanotic neuroectodermal tumour of infancy, as cited by some authors. ${ }^{13} 14$ Of these 76 tumour, ${ }^{7} 55$ were in the maxilla, seven each in the skull and mandible, three in the epididymis, two in the skin, and one each in the uterus and mediastinum. Seventy-three patients were within 1 year of age ( 3 weeks to 12 months). Only four persons were adults $(23,24$, 41 , and 67 years of age). The sex was stated in
71 patients: 34 were male, and 37 were female. Thus, the extracranial melanotic tumours had no sexual preponderance, in comparison to the intracranial variety. However, the male preponderance in the latter category is uncertain because of the small number of cases.

The prognosis has been favourable for the extracranial melanotic tumours, but this can be related to the locations allowing extensive or even total resection. ${ }^{14}$ Nevertheless, recurrence and even widespread metastases have been reported. ${ }^{15}$ By contrast, the intracranial melanotic tumours often caused death, because they were difficult to excise completely, being inaccessible, as in the mesencephalon with involvement of the brainstem in our case. However, favourable prognosis was also observed following surgical removal. ${ }^{11}$ The diverse names ${ }^{13} 14$ indicate the different opinions concerning the origin of the tumours, but it was thought to be the neural crest by some workers. ${ }^{1316-18}$ The presence of a large amount of urinary excretion of vanilmandelic acid which declined after resection of the growth of the anterior part of the maxilla in an infant, ${ }^{13}$ and identification of the neurofilaments in some tumour cells ${ }^{17}{ }^{18}$ further supported the neural crest origin of these melanotic neoplasms.

The presence of melanin in a neoplasm does not indicate that it is a malignant melanoma. Many tumours of the neural crest origin which do not usually contain this pigment have been melanotic, such as ganglioneuroma and ganglioneuroblastoma, ${ }^{19-21}$ Schwannoma, ${ }^{22-25}$ neurofibroma, ${ }^{26}{ }^{27}$ and meningioma. ${ }^{28-30}$ Granules of melanin are found in both mesenchymal and neuroectodermal type cells, as in Schwann's cells, neurons, neuroglia, and choroidal epithelium. ${ }^{2} 321$ Based on the work of Barden, ${ }^{31}$ melanin may be formed by conversion of lipochrome in the process of pseudoperoxidation by certain metallic elements rather than by enzymatic catalytic oxidation. ${ }^{2} 332$ If this view is accepted, it explains the finding of melanin in some mesenchymal, neuroectodermal, or in mixed mesenchymal and neuroepithelial tumours other than malignant melanoma. Moreover, it explains the occurrence of melanin-laden adrenal cortical epithelial cells in a "melanotic hamartoma (retinal anlage tumour)" of the epididymis in which melanin was present in the epithelial cells of a heterotopic nodule of the adrenal cortex related to the tumour, ${ }^{33}$ and in a black adenoma of the adrenal cortex. ${ }^{34}$ Furthermore, it explains the presence of melanin in a "malignant melanoma of the choroid plexus epithelium." 35 However, it is suggested that such a malignant melanin-laden 
epithelial tumour of the choroid plexus, a glandular structure, should be diagnosed as primary melanotic adenocarcinoma ${ }^{2}{ }^{36}{ }^{37}$ rather than as a "malignant melanoma." 35 We do not consider the mesencephalic melanotic tumour of our case to be a teratoma. The multiple elements in the lesion were not all foreign to the brain.

The present author concurs with Hahn et al ${ }^{11}$ that the undifferentiated small tumour cells could be ependymal cells, sympathicoblasts or neuroblasts, or other dedifferentiated neuropithelial derivatives such as the medulloblasts. Some neuroepithelial derivatives, namely, ependyma and choroidal epithelium, tend to form rosettes, tubules, villi, and clefts as well as to produce mucin. ${ }^{353638-40}$ These characteristics may be maintained when neuroepithelial derivatives become neoplastic. Formation of rosettes is also well known in sympathicoblastoma or neuroblastoma, medulloblastoma, and retinoblastoma. Nevertheless, these undifferentiated small cells could also be mesenchymal in origin that is cells from lymphoma and undifferentiated sarcoma. ${ }^{41-43}$ Reticulin fibres within the tumour, especially those wrapped around the individual neoplastic cells, are helpful in distinguishing undifferentiated sarcoma from undifferentiated neuroepithelial tumour cells. Reticulin fibres would be absent or insignificantly present among the latter, as in our case.

I do not consider the intracranial melanotic tumours under this discussion as variants of medulloblastoma as contended by others, ${ }^{4-6} 10$ because they can arise outside the cerebellum, as in the third ventricle, ${ }^{7}$ temporal lobe, ${ }^{12}$ and mesencephalon of this example. Indeed, undifferentiated cerebellar tumours having foci of spongioblastic, oligodendroglial, astrocytic, and neuronal differentiations; and neoplastic cells in pseudopalisades around the necrotic foci as well as papillary formations $s^{5}$ should be diagnosed as undifferentiated neuroepithelial neoplasms which may contain medulloblastomas, rather than as medulloblastomas. For these various reasons, I regard the diagnosis of "melanotic neuroepithelial neoplasm" of the mesencephalon as appropriate. The presence of mucin within some tumour cells further supports indirectly the origin of the present neoplasm from the neuroepithelium. Mucin is not a specific product of neuroepithelium, but this epithelium secretes mucin in both physiological and pathological conditions. ${ }^{63-384044-46}$ The same substance was also observed in the oligodendroglioma, ${ }^{6}$ an element in the present mesencephalic melanotic tumour, but $I$ have not been able to trace in- formation from the medical literature concerning production of this material by the medulloblastoma.

Origin of the tumour Melanotic neuroepithelial neoplasms may arise from the neural tube or crest when they are intracranial, or from the neural crest when extracranial. The neuroepithelium of the neural tube differentiates into neurons and neuroglia of the neuraxis and choroidal epithelium. These derivatives may mingle in a neoplasm. We have emphasised the bidermal (ectomesenchymal) origin of the neural crest; 4849 it is formed by mingling of the mesenchyme and developing neuroepithelium as bilateral longitudinal cellular cords where the neural folds join with the superficial ectoderm. After fusion of the edge of the neural folds and separation of the latter from the overlying ectoderm, the neural crests join and assume a dorsolateral position in relation to the neural tube. The neural crest cells give rise to several structures along both neuroectodermal and mesenchymal lines. The cells from the cranial part of the crest which migrate to the region of the future head differentiate into the cranial and some spinal neural ganglions, autonomic ganglions, sheath cells of the cranial and some spinal nerves, leptomeninges, melanoblasts and melanocytes, membrane bones of the skull, jaws, cartilage, odontoblasts, subcutaneous connective tissue, and chromaffin system. ${ }^{5051}$ The derivatives of the neural crest, thus, are widespread throughout the body, and may mingle with those of the neural tube in a neoplasm.

Thus, it is not surprising to encounter tumours of combined neuroepithelial derivatives as in the present case, of mixed mesenchymal derivatives as in a combined sarcoma of the nerve sheath and rhabdomyosarcoma, ${ }^{48}$ or of mixed mesenchy$\mathrm{mal}$ and neuroectodermal derivatives (ectomesenchymoma) as previously reported both intracranially 41-43 53-55 and extracranially. ${ }^{49} 5657$ These mixed tumours may arise from the derivatives of the neural tube, neural crest, or combined neural tube and crest. It is likely that some reported "progonomas" and "retinal anlage tumours" are neoplasms of mixed mesenchymal and neuroepithelial origin. For example, Williams $^{14}$ noted osseous tissue in a maxillary tumour he diagnosed as "melanotic ameloblastoma (progonoma)." A "melanotic hamartoma (retinal anlage tumour)" of the epididymis reported by Frank and Kotin ${ }^{33}$ possessed cells and fibres reacting as smooth muscle in Masson's trichrome and Van Gieson's stains, as well as having numerous reticulin fibres among them. 
Reticulin fibres, however, were absent from the "neuroglia-like" areas. The findings in these two cases ${ }^{14}{ }^{33}$ suggest mesenchymal participation in pathogenesis of the tumours which could be combined mesenchymal and neuroepithelial neoplasms of the neural crest. The diverse locations of these melanotic tumours, ranging from the brain, cranium, jaws, mediastinum, and genitalia result from widespread as well as aberrant migration of the neural crest cells and their derivatives and of derivatives of the neuroepithelium of the neural tube.

Congenital occurrence of melanotic neuroepithelial tumours Papillary formations of the neoplastic cells and the common occurrence of the melanotic tumours in infancy, mostly in the first six months of life, strongly suggest congenital derivation. Papillae can be induced to form in the metencephalon of the chick embryo, aged 33 to 38 hours, by contact between the neuroepithelium and the surrounding mesenchyme. ${ }^{58}$ Therefore, it is likely that papillae in the tumours of this case and others were formed by contact of the neuroepithelially-derived neoplastic cells with the mesenchymal matrix at the appropriate time of development of the growth when the neuroepithelial derivatives are still capable of differentiating into papillary structures. Thus, the finding reflects congenital occurrence of the tumours, as we have concluded in the cases of neuroepithelial (colloid) cyst, another congenital lesion. ${ }^{40475960}$ Moreover, a simultaneous occurrence of brain heterotopia and melanotic neuroectodermal tumour within the same oropharyngeal mass had been reported and was detected on the first day of life. ${ }^{61}$ In the adult cases, ${ }^{11} 12$ perhaps the neural crest and tube remnants persist and subsequently undergo neoplasia.

\section{References}

1 Shuangshoti S, Panyathanya R. Neural neoplasms in Thailand. A study of 2897 cases. Neurology (Minneap) 1974; 24:1127-34.

2 Shuangshoti S, Paisoontornsook P, Netsky MG. Melanosis of the choroid plexus. Neurology (Minneap) 1976; 26:656-8.

3 Shuangshoti S, Paisoontornsook P, Netsky MG. Melanosis of the choroid plexus, ependyma, subependymal neuroglia, and dentate and trigeminal motor nuclei. Observation on the choroidal and ependymal cilia. Arch Pathol Lab Med (Chic) 1979; 103:112-5.

4 Fowler M, Simpson DA. A malignant melaninforming tumour of the cerebellum. J Pathol Bacteriol 1962; 84:307-11.

5 Rubinstein LJ, Northfield DWC. The medullo- blastoma and the so-called "arachnoidal cerebellar sarcoma." A critical re-examination of a nosological problem. Brain 1964; 87:397-412.

6 Rubinstein LJ. Tumours of the central nervous system. In: Atlas of Tumor Pathology. Second Series, Fasc 6, Washington, DC: Armed Forces Institute of Pathology, 1972: 85-104 and 135-53.

7 Stowens D, Lin T-N. Melanotic progonoma of the brain. Human Pathol 1974; 5:105-13.

8 Stowens D. Pediatric Pathology. Second edition. Baltimore: Williams and Wilkins, 1966: 401.

9 Best P. A medulloblastoma-like tumour with melanin formation. J Pathol Bacteriol 1973; 110:101-11.

10 Sung JH, Mastri AR, Segel EL. Melanotic medulloblastoma of the cerebellum. J Neuropathol Exp Neurol 1973; 32:437-45.

11 Hahn JF, Sperber EE, Netsky MG. Melanotic neuroectodermal tumors of the brain and skull. J Neuropathol Exp Neurol 1976; 35:508-19.

12 McCloskey JJ, Parker JC, Brooks WH, Blacker HM. Melanin as a component of cerebral gliomas. The melanotic cerebral ependymoma. Cancer 1976; 377:2373-9.

13 Borello EO, Gorlin RJ. Melanotic neuroectodermal tumor of infancy-A neoplasm of neural crest origin. Report of a case associated with high urinary excretion of vanilmandelic acid. Cancer 1966; 19:196-206.

14 Williams AO. Melanotic ameloblastoma ("progonoma") of infancy showing osteogenesis. J Pathol Bacteriol 1967; 93:545-8.

15 Lindahl F. Malignant melanotic progonoma. One case. Acta Pathol Scand Sect A 1970; 78:532-6.

16 Clarke BE, Parsons H. An embryological tumor of retinal anlage involving skull. Cancer 1951; 4:78-85.

17 Misugi K, Okajiam WA, Newton WA, Kmetz DR, de Lorimier AA. Mediastinal origin of a melanotic progonoma or retinal anlage tumor. Ultrastructural evidence of neural crest origin. Cancer 1965; 18:477-84.

18 Hayward AF, Fickling BW, Lucas RB. An electron microscopic study of a pigmented tumour of the jaw of infants. Br J Cancer 1969; 23:702-8.

19 Millar WG. A malignant melanotic tumor of ganglion cells arising from a thoracic sympathetic ganglion. J Pathol Bacteriol 1932; 35:351-7.

20 Kellert E, Woodruff R. Pigmented ganglionic tumor of the thorax. Cancer 1956; 9:300-5.

21 Hahn JF, Netsky MG, Butler AB, Sperber EE. Pigmented ganglioneuroblastoma. Relation of melanin and lipofuscin to Schwannoma and other tumors of neural crest origin. J Neuropathol Exp Neurol 1976; 35:393-403.

22 Hodson JJ. An intraosseous tumour combination of biological importance. Invasion of a melanotic Schwannoma by an adamantinoma. J Pathol Bacteriol 1961; 82:257-66.

23 Shillitoe AJ. Melanotic Schwannoma. J Pathol Bacteriol 1965; 90:667-8.

24 Dastur DK, Sinh H, Pandya SK. Melanotic tumor 
of the acoustic nerve. Case report. J Neurosurg 1967; 27:166-70.

25 Mandybur TI. Melanotic nerve sheath tumors. J Neurosurg 1974; 41:187-92.

26 Bird CC, Willis RA. The histogenesis of pigmented neurofibromas. J Pathol 1969; 97:631-7.

27 Harkin JC, Reed RJ. Tumors of the Peripheral Nervous System. In: Atlas of Tumor Pathology. Washington, DC: Armed Forces Institute of Pathology, 1969: 146-7.

28 Ray BS, Foot NC. Primary melanotic tumors of the meninges resemblance to meningioma. Report of two cases in which operation was performed. Arch Neurol Psychiat (Chic) 1940; 44:104-17.

29 Keegan HR, Mullan S. Pigmented meningiomas. An unusual variant. Report of a case and review of the literature. $J$ Neurosurg 1962; 19:696-8.

30 Turnbull IM, Tom MI. Pigmented meningioma. J Neurosurg 1963; 20:76-80.

31 Barden $H$. The histochemical relationship of neuromelanin and lipofuscin. J Neuropathol Exp Neurol 1969; 28:419-41.

32 Singer PA, Cate J, Ross DG, Netsky MG. Melanosis of the dentate nucleus. Neurology (Minneap) 1974; 24:156-61.

33 Frank GL, Kotin JW. Melanotic hamartoma ("retinal anlage tumour") of the epididymis. $J$ Pathol Bacteriol 1967; 93:549-54.

34 Caplan RH, Virata RL. Functional black adenoma of the adrenal cortex. A rare cause of primary aldosteronism. Am J Clin Pathol 1974; 62:97-103.

35 Beatty RA. Malignant melanoma of the choroid plexus epithelium. Case report. J Neurosurg 1972; 36:344-7.

36 Shuangshoti, Tangchai P, Netsky MG. Primary adenocarcinoma of the choroid plexus. Arch Pathol (Chic) 1971; 91:101-6.

37 Netsky MG, Shuangshoti S. The Choroid Plexus in Health and Disease. Bristol: John Wright, 1975: 19-35, 199, 200-9, 272-7.

38 Shuangshoti S, Netsky MG. Histogenesis of choroid plexus in man. Am J Anat 1966; 118: 283-315.

39 Shuangshoti S, Netsky MG. Xanthogranuloma (xanthoma) of choroid plexus. The origin of foamy (xanthoma) cells. Am J Pathol 1966; 48: 503-33.

40 Shuangshoti S, Netsky MG. Neuroepithelial (colloid) cysts of the nervous system. Further observations on pathogenesis, location, incidence and histochemistry. Neurology (Minneap) 1966; 16:889-903.

41 Shuangshoti S, Netsky MG. Neoplasms of mixed mesenchymal and neuroepithelial origin. Relation to "monstrocellular sarcoma" or "giant-celled glioblastoma." J Neuropathol Exp Neurol 1971; 30:290-309.

42 Shuangshoti S, Netsky MG. Brain tumor of mixed mesenchymal and neuroepithelial origin. Case report. J Neurosurg 1971; 34:808-13.

43 Shuangshoti S, Samranvej P. Hypothalamic and pancreatic lesions with diabetes mellitus. $J$ Neurol Neurosurg Psychiatry 1975; 38:1003-7.

44 Shuangshoti S, Roberts MP, Netsky MG. Neuroepithelial (colloid) cysts. Pathogenesis and relation to choroid plexus and ependyma. Arch Pathol (Chic) 1965; 80:214-24.

45 Shuangshoti S, Netsky MG. Choroid plexus and paraphysis in lower vertebrates. J Morphol 1966; 120:157-88.

46 Shuangshoti S, Netsky MG. Human choroid plexus. Morphologic and histochemical alterations with age. Am J Anat 1970; 128:73-96.

47 Shuangshoti S, Rungruxirivorn S, Netsky MG. Combined occurrence of mucin-producing ependymoma and neuroepithelial (colloid) cysts. $J$ Neuropathol Exp Neurol 1979; 38:72-9.

48 Shuangshoti S, Chongchet V. Malignant mesenchymoma of ulnar nerve. Combined sarcoma of nerve sheath and rhabdomyosarcoma. J Neurol Neurosurg Psychiatry 1979; 42:524-8.

49 Shuangshoti C, Cutchavaree R. Parapharyngeal neoplasm of mixed mesenchymal and neuroepithelial origin. Arch Otolaryngol (Chic) 1980; in press.

50 Johnson $M$. A radioautographic study of the migration and fate of cranial neural crest cells in the chick embryo. Anat Rec 1966; 156:143-55.

51 Weston JA. The Migration and Differentiation of Neural Crest Cells. In: Abercrombie H, Brachet $\mathrm{J}$, King $\mathrm{T}$, eds. Advances in Morphogenesis. Vol 8. New York: Academic Press, 1970: 41-144.

52 Holimon JL, Rosenblum WI. "Gangliorhabdomyosarcoma." A tumor of ectomesenchyme. Case report. J Neurosurg 1971; 34:417-22.

53 Shuangshoti S, Netsky MG, Jane JA. Neoplasms of mixed mesenchymal and neuroepithelial type with consideration of the relationship between meningioma and neurilemmoma. $J$ Neurol Sci 1971 ; 14:277-91.

54 Shuangshoti S. Neoplasm of mixed mesenchymal and neuroepithelial origin. Liposarcomatous meningioma combined with gliomas. J Neurol Neurosurg Psychiatry 1973; 36:377-82.

55 Shuangshoti S, Panyathanya R. Neoplasm of mixed mesenchymal and neuroepithelial origin of the optic nerve. Br J Ophthalmol 1977; 61:390-3.

56 Naka A, Matsumoto S, Shirai T, Itoh $T$. Ganglioneuroblastoma associated with malignant mesenchymoma. Cancer 1975; 36:1050-6.

57 Karcioglu Z, Someren A, Mathes S. Ectomesenchymoma. A malignant tumor of migratory neural crest (ectomesenchyme) remnants showing ganglionic, Schwannian, melanocytic and rhabdomyocytic differentiation. Cancer 1977; 39:2486-96.

58 Birge WJ. Induced choroid plexus development in the chick metencephalon. J Comp Neurol 1962; 118:89-96.

59 Shuangshoti S, Phisitbutr M, Kasantikul V, Netsky MG. Multiple neuroepithelial (colloid) cysts. Associated with other congenital anomalies. Neurology (Minneap) 1977; 27:561-6. 
60 Shuangshoti S, Netsky MG, Switter DJ. Combined congenital vascular anomalies and neuroepithelial (colloid) cysts. Neurology (Minneap) 1978; 28:552-5.
61 Lee SC, Henry MM, Gonzalez-Crussi F. Simultaneous occurrence of melanotic neuroectodermal tumor and brain heterotopia in the oropharynx. Cancer 1976; 38:249-53. 